\title{
What explains the association between neighborhood-level income inequality and the risk of fatal overdose in New York City?
}

\author{
Arijit Nandi $^{\mathrm{a}, \mathrm{b}}$, Sandro Galea ${ }^{\mathrm{b}, \mathrm{c}, *}$, Jennifer Ahern ${ }^{\mathrm{b}, \mathrm{c}, \mathrm{d}}$, Angela Bucciarelli ${ }^{\mathrm{b}}$, \\ David Vlahov $^{\mathrm{a}, \mathrm{b}}$, Kenneth Tardiff ${ }^{\mathrm{e}}$ \\ a Department of Epidemiology, Johns Hopkins Bloomberg School of Public Health, Baltimore, MD, USA \\ ${ }^{\mathrm{b}}$ Center for Urban Epidemiologic Studies, The New York Academy of Medicine, NY, USA \\ ${ }^{c}$ Department of Epidemiology, University of Michigan School of Public Health, Ann Arbor, MI, USA \\ ${ }^{\mathrm{d}}$ Department of Epidemiology, University of California Berkeley School of Public Health, Berkeley, CA, USA \\ ${ }^{\mathrm{e}}$ Department of Psychiatry, Weill Medical College of Cornell University, USA
}

Available online 4 April 2006

\begin{abstract}
Accidental drug overdose is a substantial cause of mortality for drug users. Using a multilevel case-control study we previously have shown that neighborhood-level income inequality may be an important determinant of overdose death independent of individual-level factors. Here we hypothesized that the level of environmental disorder, the level of police activity, and the quality of the built environment in a neighborhood mediate this association. Data from the New York City (NYC) Mayor's Management Report, the NYC Police Department, and the NYC Housing and Vacancy Survey were used to define constructs for the level of environmental disorder, the level of police activity and the quality of the built environment, respectively. In multivariable models the odds of death due to drug overdose in neighborhoods in the top decile of income inequality compared to the most equitable neighborhoods decreased from 1.63 to 1.12 when adjusting for the three potential mediators. Path analyses show that the association between income inequality and the rate of drug overdose mortality was primarily explained by an indirect effect through the level of environmental disorder and the quality of the built environment in a neighborhood. Implications of these findings for the reduction of drug overdose mortality associated with the distribution of income are discussed.
\end{abstract}

(C) 2006 Elsevier Ltd. All rights reserved.

Keywords: Income inequality; Drug overdose; Police; Disorder; Built environment; Neighborhood

\footnotetext{
*Corresponding author.

E-mail addresses: anandi@jhsph.edu (A. Nandi), sgalea@umich.edu (S. Galea), jahern@nyam.org (J. Ahern), abucciarelli@nyam.org (A. Bucciarelli),dvlahov@nyam.org (D. Vlahov), kjtardif@med.cornell.edu (K. Tardiff).
}

\section{Introduction}

Drug overdose is common among drug users (Darke \& Hall, 2003). It is estimated that approximately $60-70 \%$ of drug users experience an overdose during their lifetime (Sergeev, Karpets, Sarang, \& Tikhonov, 2003; Warner-Smith, Darke, \& Day, 2002) and that approximately $70-90 \%$ of drug users 
witness an overdose (Darke \& Hall, 2003; Sergeev et al., 2003). In a sample of drug users from the Russian Federation, an estimated $15 \%$ of drug users reported witnessing a fatal drug overdose (Sergeev et al., 2003) and in a sample of UK injection drug users, $79 \%$ had a personal acquaintance die from an accidental overdose (Bennett \& Higgins, 1999). Drug overdose is associated with considerable morbidity (Warner-Smith et al., 2002) and studies have shown that drug users have mortality rates several magnitudes greater than rates for their peers, with much of this excess mortality attributable to drug overdose (Joe \& Simpson, 1987). Death rates from drug overdose have been increasing throughout the United States (US) over the past decade (CDC, 2004).

Many studies have attempted to identify the factors associated with the increased risk of accidental drug overdose. These factors can generally be categorized as individual/drug user factors (e.g., gender, age, race/ethnicity, sexual orientation) (Darke \& Hall, 2003; Latkin, Hua, \& Tobin, 2004), drug-related factors (e.g., type of drug, route of administration, concomitant drug use, duration of drug use, treatment status) (Bennett \& Higgins, 1999; Darke \& Hall, 2003; Sergeev et al., 2003), and factors relating to the circumstances of drug use (e.g., location of overdose, network size) (Latkin et al., 2004). Additionally, as part of the growing epidemiologic interest in determining whether socioeconomic processes operating at the group level exert contextual influences on individual health outcomes (Diez Roux, 1998), a few studies have assessed the role that characteristics of neighborhoods or other environments, such as levels of absolute and relative income, play in determining the risk of drug overdose (Galea et al., 2003; Marzuk et al., 1997).

In contrast to the well-established relation between absolute income and health (Marmot, 2002), the study of relative income and health is relatively new. Several recent reviews have summarized the best available empiric evidence about the contextual effect of income inequality on population health independent of the compositional association between aggregate individual income and health (Lynch et al., 2004; Subramanian \& Kawachi, 2004; Wilkinson \& Pickett, 2006). The empirical evidence suggests that the relation between income inequality and population health may be limited to particular contexts. Specifically, evidence for an independent contextual effect of income inequality on health, usually assessed as self-rated health or mortality, appears more robust within the US and at higher levels of aggregation (i.e., states), rather than across countries or at smaller levels (Subramanian \& Kawachi, 2004).

The importance of income inequality as a characteristic of US states provides an indication of the primary mechanisms hypothesized to link income inequality and health (Subramanian \& Kawachi, 2004). Two general explanations have been posited to explain the link between income inequality and health outcomes (Kawachi \& Kennedy, 1999). First, it has been suggested that income inequality adversely affects health through an association with inadequate investments in physical and social infrastructure and attendant limitations in material resources that may be salutary (Lynch, Smith, Kaplan, \& House, 2000). According to this interpretation, income inequality should be measured at a geographic level congruent with the political and economic processes that may underlie disparities in physical and social infrastructure hypothesized to influence a particular health outcome. The more consistent relation between income inequality and health at the level of US states may implicate political mechanisms mediated by variations in state spending (Subramanian \& Kawachi, 2004) and a few studies have provided preliminary evidence for this interpretation (Lynch et al., 2000), including one report which documented associations between income inequality and levels of social expenditures (Kaplan, Pamuk, Lynch, Cohen, \& Balfour, 1996). Second, it has been postulated that less egalitarian societies engender divisive social interactions, which generate poorer health directly through physiological mechanisms or indirectly by fostering stress-induced deleterious behaviors (Wilkinson, 1997). Again, this suggests that income inequality should be measured at a level that captures the psychosocial processes posited to influence a certain health outcome. Other studies provide support for this interpretation (Kawachi, Kennedy, Lochner, \& Prothrow-Stith, 1997), including a study which found that levels of investment in social capital mediated the association between income inequality and mortality in US states (Kawachi et al., 1997). However, relatively few studies have assessed the potential pathways that may explain how income inequality may be associated with poor health (Lynch et al., 2004).

The association between income inequality and the likelihood of fatal drug overdose (Galea et al., 2003) may be explained by one or both of the pathways discussed here. In areas characterized by higher 
income inequality, low levels of social cohesion can manifest in environmental or physical disorder (e.g., litter on the street) (Ross \& Jang, 2000) and in a lower likelihood of residents intervening when witnessing an overdose. Although overdoses are usually witnessed (Darke \& Hall, 2003), persons present during a drug overdose seek medical help in fewer than half of all fatal drug overdoses (Darke, Ross, \& Hall, 1996). Therefore, the level of environmental disorder could partially explain the relation between income inequality and the likelihood of fatal drug overdose. Fears of police involvement or of criminal prosecution are primary reasons why persons who witness overdose may be reluctant to call for help and may contribute to overdose mortality (Darke et al., 1996). This general mistrust and fear, congruent with an erosion of social capital, may be more prevalent in areas characterized by higher income inequality (Kawachi et al., 1997) and more police activity. Therefore, the level of police activity could partially explain the association between income inequality and the likelihood of fatal drug overdose. Additionally, qualities of the built environment have been linked to health among residents of urban areas (Evans, 2003), including mortality from accidental drug overdose (Hembree et al., 2005). Psychosocial mechanisms have been postulated to underlie this association (Weich et al., 2002). Persons subject to psychosocial stress may be more vulnerable both to overdosing on drugs (Sinha, 2001) and to death from a drug overdose. In addition, the quality of the built environment may contribute to drug overdose mortality in areas marked by higher income inequality through the presence of features conducive to drug use and overdose, such as dilapidated and abandoned buildings. The presence of secluded areas where drugs are used may increase drug overdose mortality by preventing timely responses to overdose events (Dovey, Fitzgerald, \& Choi, 2001). Therefore, the quality of the built environment may also partially mediate the association between income inequality and the likelihood of fatal drug overdose.

We suggest that the pathways linking income inequality and the likelihood of drug overdose mortality may be particularly important within cities at the neighborhood level. Citing conflicting empirical support for the income inequality hypothesis from studies conducted in smaller areas, some authors have suggested that there is less evidence for an independent contextual income inequality effect at lower levels of aggregation (e.g., census tracts) (Soobader \& LeClere, 1999; Wilkinson, 1997). However, many studies conducted at lower levels of aggregation have been carried out in international settings more egalitarian than the US, where associations between income inequality and health have been inconsistent (Lynch et al., 2004; Subramanian \& Kawachi, 2004; Wilkinson \& Pickett, 2006). These studies then potentially conflate the issues of geographic scale and geographic setting. Urban areas are regulated by local civic hierarchies (Galea, Freudenberg, \& Vlahov, 2005) that could plausibly influence both the material and psychosocial explanations for associations between income inequality and the likelihood of drug overdose. The role of income inequality at the intra-urban neighborhood level may be particularly germane in the case of cities where well-established neighborhoods have political and social a priori significance for their residents. Although few intra-urban assessments of the relation between income inequality and population health have been conducted, our recent finding that living in a New York City (NYC) neighborhood characterized by greater income inequality is associated with a greater likelihood of accidental drug overdose death than death due to other accidents independent of other characteristics of decedents or of their neighborhoods (Galea et al., 2003) suggests that it may be important to consider income inequality at this level in such urban contexts.

Although there is an extensive literature on the relations between features of the social environment and various health outcomes, the literature about the mechanisms that may explain these observed multilevel relationships is much more limited. This paper assesses potential mechanisms that explain the previously documented observation that the likelihood of fatal drug overdose was higher in NYC neighborhoods characterized by higher income inequality (Galea et al., 2003). Specifically, we hypothesized that the level of environmental disorder, the level of police activity and the quality of the built environment in a neighborhood mediate the relation between income inequality and the likelihood of fatal drug overdose.

\section{Data collection}

\section{Mortality and demographics}

Mortality and demographic data were collected from the Office of the Chief Medical Examiner of NYC (OCME). All cases of fatal accidents involving 
adults aged 15-64 in NYC during 1996 were identified through a manual review of medical files at the OCME. The OCME is responsible for assessing all deaths of persons believed to have died in an unnatural manner in NYC. Therefore, all accidental deaths due to overdose and all accidental non-overdose deaths in NYC would have been reviewed by the OCME and included in this sample. The OCME investigators use the decedent's medical history, the circumstances and environment of the fatality (e.g., was the decedent found in a "shooting gallery"?), autopsy findings and laboratory data to attribute cause of death to each case reviewed. Deaths caused by accidental drug overdoses were considered cases in these analyses and deaths due to other accidents were considered controls. Non-overdose accidental deaths included in these analyses were poisoning, asphyxiation, drowning, firearm deaths, stabbing, electrocutions, blunt trauma, crushing, falls, vehicular accidents, burns, explosions, environmental exposures and other accidents. Deaths caused by human intent are not considered accidents by the OCME and were not included in these analyses. Individual data regarding age, gender, race/ethnicity and residence were collected for all decedents from the OCME files.

NYC is divided into 59 residential community districts (CDs). They include, e.g., the Upper West Side (CD \#7) and Bedford Stuyvesant neighborhoods (CD \#3 in Brooklyn). Residents of NYC identify with their neighborhoods. In fact, CDs were initially defined by a resident consultative process organized by the Office of City Planning to reflect residents' own descriptions of neighborhoods in the 1970s. CDs delineate meaningful neighborhoods within NYC, each with an administrative community board. Decisions made by the community board influence material resources in the neighborhood as well as how features of the local social and economic environment may influence health and behavior. These CDs, as such, have political and social a priori significance for their residents. Although the CDs are not demographically homogenous, they represent neighborhoods that have been shown to affect resident behavior and health (Galea et al., 2003; Marzuk et al., 1997) and were used as neighborhood units in these analyses. These CDs will be referred to as neighborhoods hereafter. All cases and controls were geocoded to their neighborhood of residence. Decedents who resided outside of NYC, did not have residential information, or were classified as homeless were excluded from this analysis. We used 1990 US
Census data to obtain mean income and percent Black respondents in each neighborhood (Bureau of the Census, 1990). All autopsied OCME cases undergo toxicological screening. We used the proportion of accidental non-overdose decedents who were positive for any illegal drug other than marijuana to represent the level of drug use in a neighborhood (Galea et al., 2003).

\section{Environmental disorder}

We defined our construct for the level of environmental disorder as a measure of the cleanliness of neighborhood sidewalks. The percent of acceptably clean sidewalks was obtained from the Fiscal 2002 NYC Mayor's Management Report (NYC Mayor's Office of Operations, 2002). The Mayor's Management Report represents a compilation of performance indicators from 41 NYC agencies. Information from the 2002 report, which presents data for each NYC neighborhood, was collected from the interactive "My Neighborhood Statistics" feature on the Mayor's Management Report website and used in these analyses. As defined by the report, the percentage of sidewalks that met an acceptable standard of cleanliness was based upon a seven-point picture-based rating scale designed to reflect the public perception of acceptable cleanliness levels; values represent the annual average of twice-monthly ratings of a citywide street sample obtained from Mayor's Office field inspectors (NYC Mayor's Office of Operations, 2002).

\section{Police activity}

We defined our construct for the level of police activity by assessing the burden of misdemeanor crime in a neighborhood. We collected data on the mean number of misdemeanor arrests in a neighborhood. The total number of misdemeanor arrests in each year between 1996 and 1999 for each neighborhood was obtained from the NYC Police Department via Infoshare Online, an interactive database sponsored by Community Studies of New York, Inc. that includes data on NYC areas and residents compiled from the Census and a variety of NYC government agencies (Infoshare Online).

\section{Quality of the built environment}

We defined the quality of the built environment of a neighborhood as a measure of the percent of 
buildings in dilapidated condition, obtained from the 1999 NYC Housing and Vacancy Survey (NYCHVS). Approximately 15,550 occupied housing units were appraised by the US Census Bureau in the 1999 NYCHVS and considered in these analyses (Bureau of the Census, 1999). As defined by the NYCHVS, a building was considered dilapidated if its exterior featured one or more critical defects (e.g., major open holes), a number of intermediate defects (e.g., missing stair railings), or was of poor original construction and thus incapable of providing safe and adequate shelter for occupants (Bureau of the Census, 1999). The boundaries demarcating sub-borough areas, the geographic units used in the NYCHVS, approximated the neighborhood boundaries used in this study with few exceptions. In two areas of the Bronx and Manhattan two neighborhoods were combined into one sub-borough; in our analyses, the value of the larger sub-borough was assigned to the two neighborhoods from which it was composed. The median number of housing units sampled per neighborhood was 245 with a range of $187-702$.

\section{Income inequality}

We used two highly correlated measures of income inequality: the Gini coefficient and the percent of total income earned by the lowest earning $70 \%$ of households (Galea et al., 2003). The Gini coefficient measures income distribution and the extent of inequality. We used 1990 Census data to calculate the Gini coefficient for each neighborhood (Bureau of the Census, 1990). A Gini coefficient of zero denotes a perfectly equitable income distribution whereas a Gini coefficient of one represents maximal maldistribution. Further details on the calculation of the Gini coefficient are provided elsewhere (Galea et al., 2003). The percent of total income earned by the lowest earning $70 \%$ of households was estimated from 1990 US Census data by calculating the percent of the total income value in each neighborhood that was earned by the poorest $70 \%$ of households (Bureau of the Census, 1990). Therefore, neighborhoods with a value closer to $70 \%$ have a more equitable income distribution.

\section{Statistical analyses}

We conducted two types of analyses: (i) multilevel analyses with individual-level and neighborhoodlevel covariates and an individual-level outcome and (ii) ecological analyses conducted entirely at the neighborhood-level. With respect to the first type of analyses, we described the overdose and accident death rates by neighborhood and used chi-square tests and $t$-tests as appropriate to test for demographic differences between cases (overdose decedents) and controls (accident decedents). We used logistic regression to test the bivariate relations between the covariates of interest and the likelihood of overdose fatality compared to accident fatality. The linearity of the relation between each covariate and outcome was tested using differences in loglikelihood ratios $(p<0.01)$. Evidence of a nonlinear relation between mean neighborhood income and the outcome was found. The relation between mean neighborhood income and the likelihood of drug overdose death was best described by a quadratic income term and neighborhood income was subsequently modeled in quadratic form. We used generalized estimating equations to fit multivariable marginal models that assessed the relation between each measure of income distribution and the likelihood of fatal drug overdose. This method accounts for the correlation between outcomes within higher levels (e.g., neighborhoods) without explicitly investigating the intra-neighborhood correlation and has been used extensively in other multilevel analyses, and is a valid approach for the estimation of the association between neighborhood characteristics and health (Ahern, Pickett, Selvin, \& Abrams, 2003; Merlo, 2003; Zeger \& Liang, 1986). Five multivariable models were developed for each measure of income distribution. In the initial model, we regressed neighborhood-level variables (income in quadratic form, neighborhood racial composition, neighborhood drug use, income distribution) and individual-level variables (age, race, sex) against the rate of drug overdose mortality. In the subsequent three models, we individually adjusted the regression models for the three constructs hypothesized to mediate the relation between income distribution and the likelihood of fatal drug overdose (i.e., environmental disorder, police activity, quality of the built environment). Finally, in the fifth model, we adjusted the regression models for all three mediators together. To assess the magnitude of the relation between income distribution and the likelihood of drug overdose before and after adjusting for mediator variables, we calculated the odds ratio for percentiles of both measures of income distribution (for the range of Gini coefficients and proportion income earned by the lowest 
earning $70 \%$ of households), setting the midpoint of the lowest decile as the referent. In the ecological analyses, we assessed the effects of income inequality and the mediator variables on drug overdose mortality using a path analysis based on a recursive causal model in which income inequality affects the rate of drug overdose mortality, calculated for each neighborhood as the number of fatal drug overdoses per 100,000 residents, through its impact on environmental neighborhood disorder, the level of neighborhood police activity and the quality of the built environment.

\section{Results}

The baseline characteristics of the study population are presented in Table 1. Overall, 725 overdose deaths and 453 accident deaths were included in the analyses. Males represented $76.3 \%$ of overdose deaths compared to $78.8 \%$ of accident deaths. Overdose decedents were more likely to be Black than accident decedents $(37.2 \%$ vs. $33.5 \%)$. The mean age was $40.4 \mathrm{yr}$ for overdose decedents and $40.6 \mathrm{yr}$ for accident decedents. On average, neighborhood per capita income was similar for both groups $(\$ 14,400$ for overdose decedents vs. $\$ 14,600$ for accident decedents). On average, overdose deaths were more common in neighborhoods with a higher prevalence of drug use $(26.4 \%$ vs. $21.0 \%$ for accident decedents), greater environmental disorder measured by the percent of acceptably clean sidewalks $(86.3 \%$ vs. $87.5 \%$ for accident decedents), greater police activity measured by per capita misdemeanor arrests (0.035 vs. 0.029 for accident decedents), more deteriorated built environment measured by the percent of dilapidated housing units $(1.3 \%$ vs. $1.0 \%$ for accident decedents), higher Gini coefficient ( 0.452 vs. 0.443 for accident decedents), and lower proportion of income earned by the lowest earning $70 \%$ of households $(37.9 \%$ vs. $38.9 \%$ for accident decedents). The median number of neighborhood overdose decedents was 10 (range 0-33) and the median number of accident decedents was 7 (range 1-17). Excluded from the analysis due to missing residence information were 234 decedents; these decedents did not differ appreciably in demographic information from the included decedents.

Table 2 shows the unadjusted relations between individual-level and neighborhood-level covariates of interest and the likelihood of overdose mortality in logistic regression models. Less equitable income distribution, as measured by the Gini coefficient $(p<0.0001)$ and the proportion of income earned by the lowest earning $70 \%$ of households $(p<0.0001)$, was associated with a greater likelihood of drug

Table 1

Characteristics of overdose and accident deaths, NYC (1996); $N=1178$

\begin{tabular}{|c|c|c|c|c|c|}
\hline \multirow[b]{2}{*}{ Demographic characteristics } & \multicolumn{2}{|c|}{ Overdose deaths $(n=725)$} & \multicolumn{2}{|c|}{ Accident deaths $(n=453)$} & \multirow[t]{2}{*}{$p$-Value ${ }^{\mathrm{a}}$} \\
\hline & $N$ & $\%$ & $N$ & $\%$ & \\
\hline \multicolumn{6}{|l|}{ Gender } \\
\hline Male & 553 & 76.3 & 357 & 78.8 & \multirow[t]{2}{*}{0.31} \\
\hline Female & 172 & 23.7 & 96 & 21.2 & \\
\hline \multicolumn{6}{|l|}{ Race/Ethnicity } \\
\hline White & 233 & 32.1 & 135 & 29.8 & \multirow[t]{4}{*}{$<0.0001$} \\
\hline Black & 270 & 37.2 & 152 & 33.5 & \\
\hline Hispanic & 215 & 29.7 & 129 & 28.5 & \\
\hline Other race & 7 & 1.0 & 37 & 8.2 & \\
\hline Neighborhood characteristics & Mean & SD & Mean & SD & \\
\hline Gini coefficient ${ }^{\mathrm{b}}$ & 0.452 & 3.6 & 0.443 & 3.8 & $<0.0001$ \\
\hline Percent income earned by lowest earning $70 \%$ of households & 37.9 & 3.4 & 38.9 & 3.5 & $<0.0001$ \\
\hline Age & 40.4 & 8.7 & 40.6 & 13.5 & 0.69 \\
\hline Per capita income & $\$ 14,400$ & $\$ 10,200$ & $\$ 14,600$ & $\$ 9,000$ & 0.77 \\
\hline Percent of accidents with drugs detected & 26.4 & 19.9 & 21.0 & 18.5 & $<0.0001$ \\
\hline Percent Black residents & 31.2 & 28.1 & 29.5 & 26.9 & 0.30 \\
\hline Percent acceptably clean sidewalks & 86.3 & 7.9 & 87.5 & 7.4 & 0.01 \\
\hline Per capita misdemeanor arrests & 0.035 & 0.043 & 0.029 & 0.038 & 0.02 \\
\hline Percent housing units dilapidated & 1.3 & 1.8 & 1.0 & 1.4 & 0.002 \\
\hline
\end{tabular}

${ }^{\mathrm{a}} \mathrm{Chi}$-square tests for categorical variables and $t$-test for continuous variables.

${ }^{\mathrm{b}}$ Ranges from 0 (perfectly equitable income distribution) to 1 (maximal maldistribution). 
overdose mortality. Lower neighborhood income and the quadratic form of income were significantly associated with the likelihood of drug overdose

Table 2

Unadjusted relations between individual and neighborhood-level covariates and overdose mortality, NYC (1996); $N=1178$

\begin{tabular}{llc}
\hline Characteristic & Beta(SE) & $p$-Value \\
\hline Gini coefficient $^{\mathrm{a}}$ & $0.0709(0.0170)$ & $<0.0001$ \\
Percent income among $^{\text {lowest earning 70\% }}$ & $-0.0858(0.0174)$ & $<0.0001$ \\
Age & $-0.0022(0.0055)$ & 0.69 \\
Male $^{\mathrm{b}}$ & $-0.1298(0.1448)$ & 0.37 \\
Black $^{\mathrm{c}}$ & $-0.0084(0.1430)$ & 0.95 \\
Hispanic $^{\mathrm{c}}$ & $-0.0730(0.1481)$ & 0.62 \\
Other race $^{\mathrm{c}}$ & $-2.2034(0.3878)$ & $<0.0001$ \\
Income $^{\text {Income }}{ }^{2}$ & $-0.6095(0.2482)$ & 0.01 \\
Percent accidents with $^{\text {drugs detected }}$ & $0.1099(0.0425)$ & 0.01 \\
Percent Black residents & $0.0151(0.0036)$ & $<0.0001$ \\
Percent acceptably clean & $-0.0018(0.0028)$ & 0.53 \\
sidewalks & & 0.008 \\
Per capita misdemeanor & $3.8939(3.0270)$ & 0.20 \\
arrests & & \\
Percent housing units & $0.1188(0.0282)$ & $<0.0001$ \\
dilapidated & & \\
\hline
\end{tabular}

\footnotetext{
${ }^{\text {a }}$ Ranges from 0 (perfectly equitable income distribution) to 1 (maximal maldistribution).

${ }^{\mathrm{b}}$ Female referent.

${ }^{\mathrm{c}}$ White race referent.
}

mortality ( $p=0.01$ for both terms). The likelihood of drug overdose mortality was associated with a greater level of neighborhood drug use $(p<0.0001)$. Environmental neighborhood disorder and the quality of the built environment were both associated with the likelihood of overdose mortality ( $p=0.008$ and $p<0.0001$, respectively).

Multivariable models assessing the adjusted relation between the Gini coefficient and the likelihood of overdose mortality are presented in Table 3 . The Gini coefficient was a significant predictor of the likelihood of drug overdose in NYC neighborhoods before adjusting for hypothesized mediators ( $p=0.03$ ). In separate models adjusting for levels of environmental neighborhood disorder, levels of police activity, the quality of the built environment and all three variables together, the observed relation between the Gini coefficient and the likelihood of drug overdose mortality was no longer significant.

Table 4 presents the odds ratios for overdose death by percentiles of the Gini coefficient both before and after adjusting for mediator variables. Compared to the midpoint of the lowest Gini decile, the relative odds of death due to drug overdose was $1.63(95 \%$ confidence interval $(\mathrm{CI})=1.06,2.52)$ in neighborhoods in 95th percentile of the Gini distribution; after adjusting for the three mediator variables, the odds ratio decreased to $1.12(95 \%$

Table 3

Multi-level models of the relation between income inequality and overdose mortality, NYC (1996); $N=1178$

\begin{tabular}{|c|c|c|c|c|c|c|c|c|c|c|}
\hline \multirow[t]{2}{*}{ Characteristic } & \multicolumn{2}{|l|}{ Model 1} & \multicolumn{2}{|l|}{ Model $2^{\mathrm{a}}$} & \multicolumn{2}{|l|}{ Model $3^{\mathrm{a}}$} & \multicolumn{2}{|l|}{ Model $4^{\mathrm{a}}$} & \multicolumn{2}{|l|}{ Model $5^{\mathrm{b}}$} \\
\hline & Beta & $p$-Value & Beta & $p$-Value & Beta & $p$-Value & Beta & $p$-Value & Beta & $p$-Value \\
\hline Gini coefficient ${ }^{\mathrm{c}}$ & 4.0130 & 0.03 & 2.8352 & 0.1903 & 3.7131 & 0.0654 & 3.2646 & 0.0810 & 0.9287 & 0.6608 \\
\hline Age & -0.0064 & 0.37 & -0.0062 & 0.3904 & -0.0063 & 0.3843 & -0.0066 & 0.3511 & -0.0064 & 0.3767 \\
\hline Male $^{\mathrm{d}}$ & -0.1120 & 0.48 & -0.1133 & 0.4800 & -0.1137 & 0.4791 & -0.1023 & 0.5179 & -0.0984 & 0.5365 \\
\hline Black $^{\mathrm{e}}$ & -0.1890 & 0.29 & -0.1935 & 0.2756 & -0.1864 & 0.2949 & -0.1752 & 0.3287 & -0.1755 & 0.3235 \\
\hline Hispanic $^{\mathrm{e}}$ & -0.2822 & 0.08 & -0.2977 & 0.0752 & -0.2793 & 0.0877 & -0.2705 & 0.1000 & -0.2954 & 0.0848 \\
\hline Other race ${ }^{\mathrm{e}}$ & -2.1937 & $<.0001$ & -2.2099 & $<.0001$ & -2.2004 & $<.0001$ & -2.1828 & $<.0001$ & -2.2084 & $<.0001$ \\
\hline Income & -0.3134 & 0.19 & -0.1359 & 0.6437 & -0.3252 & 0.1896 & -0.2911 & 0.2329 & 0.0395 & 0.9019 \\
\hline$(\text { Income })^{2}$ & 0.0545 & 0.13 & 0.0335 & 0.4104 & 0.0560 & 0.1278 & 0.0539 & 0.1425 & 0.0158 & 0.7210 \\
\hline Percent Black residents & -0.0008 & 0.78 & -0.0011 & 0.7028 & -0.0009 & 0.7518 & -0.0019 & 0.5505 & -0.0029 & 0.3516 \\
\hline Percent accidents with drugs detected & 0.0105 & 0.02 & 0.0113 & 0.0021 & 0.0102 & 0.0080 & 0.0102 & 0.0053 & 0.0117 & 0.0006 \\
\hline Percent acceptably clean sidewalks & & & -0.0154 & 0.2942 & & & & & -0.0988 & 0.9157 \\
\hline Per capita misdemeanor arrests & & & & & 0.8078 & 0.3801 & & & -0.0280 & 0.0495 \\
\hline Percent housing units dilapidated & & & & & & & 0.0757 & 0.0047 & 0.1004 & 0.0003 \\
\hline
\end{tabular}

${ }^{\text {a }}$ Models 2-4 individually adjusted for three hypothesized mediators.

${ }^{\mathrm{b}}$ Model 5 adjusted for all three hypothesized mediators.

${ }^{\mathrm{c}}$ Ranges from 0 (perfectly equitable income distribution) to 1 (maximal maldistribution).

${ }^{\mathrm{d}}$ Female referent.

${ }^{\mathrm{e}}$ White race referent. 
Table 4

Odds ratios for the relation between income inequality and overdose death, unadjusted and adjusted for mediating variables; $N=1178$

\begin{tabular}{|c|c|c|c|c|c|c|c|c|}
\hline \multirow[b]{2}{*}{ Characteristic } & \multicolumn{4}{|c|}{ Initial models ${ }^{\mathrm{b}}$} & \multicolumn{4}{|c|}{ Adjusted for mediator variables ${ }^{\mathrm{c}}$} \\
\hline & $\begin{array}{l}\text { OR for } 50 \text { th } \\
\text { percentile }^{\mathrm{a}}\end{array}$ & $95 \% \mathrm{CI}$ & $\begin{array}{l}\text { OR for } 95 \text { th } \\
\text { percentile }^{\text {a }}\end{array}$ & $95 \% \mathrm{CI}$ & $\begin{array}{l}\text { OR for 50th } \\
\text { percentile }^{\mathrm{a}}\end{array}$ & $95 \% \mathrm{CI}$ & $\begin{array}{l}\text { OR for } 95 \text { th } \\
\text { percentile }^{\text {a }}\end{array}$ & $95 \%$ CI \\
\hline $\begin{array}{l}\text { Gini } \\
\text { coefficient }^{\mathrm{d}}\end{array}$ & 1.36 & $1.04-1.79$ & 1.63 & $1.06-2.52$ & 1.07 & $0.78-1.48$ & 1.12 & $0.67-1.86$ \\
\hline
\end{tabular}

\footnotetext{
${ }^{\mathrm{a}}$ In reference to 5 th percentile of the Gini coefficient.

${ }^{\mathrm{b}}$ Models adjusted for age, gender, race, neighborhood income, percent of Black residents in neighborhood and neighborhood drug use.

${ }^{\mathrm{c}}$ Models adjusted for age, gender, race, neighborhood income, percent of Black residents in neighborhood, neighborhood drug use, neighborhood misdemeanor arrests, neighborhood clean sidewalks and neighborhood dilapidated housing.

${ }^{\mathrm{d}}$ Ranges from 0 (perfectly equitable income distribution) to 1 (maximal maldistribution).
}

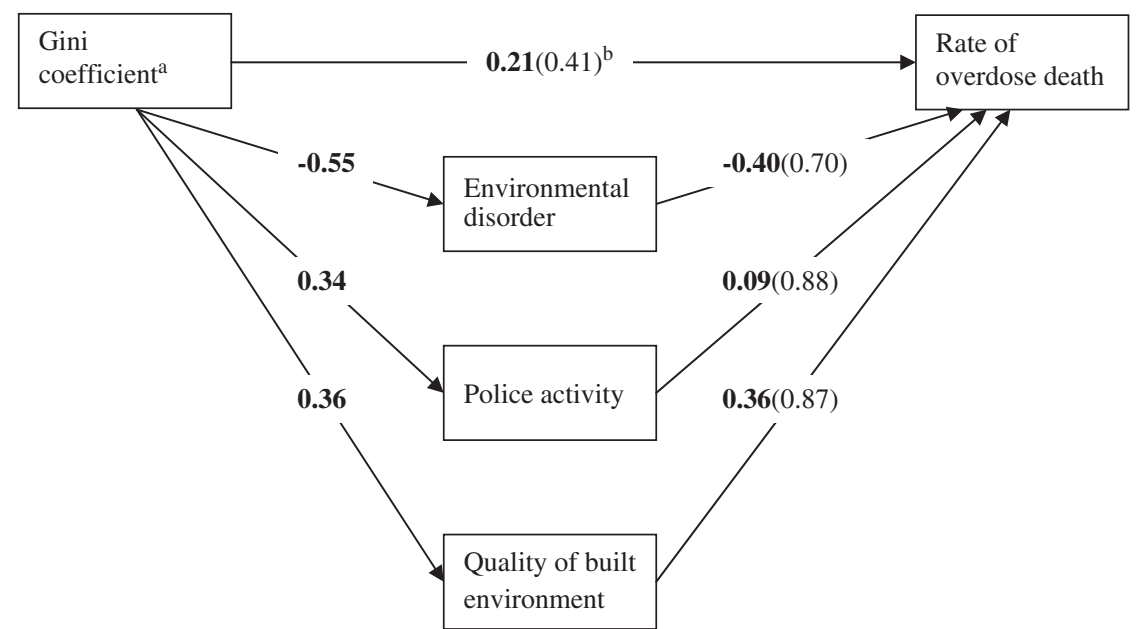

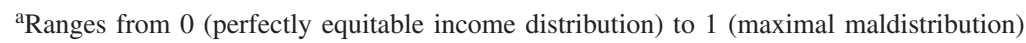

bZero-order correlations shown in parentheses; path coefficients shown in boldface

Fig. 1. Path coefficients for the effects of income inequality, per capita misdemeanor arrests, the percent of acceptably clean sidewalks and the percent of housing units in dilapidated condition in a neighborhood on the rate of overdose death; $N=59$. ${ }^{\text {a }}$ Ranges from 0 (perfectly equitable income distribution) to 1 (maximal maldistribution); ${ }^{b}$ Zero-order correlations shown in parentheses; path coefficients shown in boldface.

$\mathrm{CI}=0.67,1.86)$. Analogous findings were observed with income inequality measured as the percent of total income earned by the lowest earning $70 \%$ of households (results available upon request).

Fig. 1 presents results from path analyses measuring the effects of income distribution (i.e., the Gini coefficient) and our three hypothesized mediator variables on the rate of drug overdose mortality. The model shows that $36 \%$ of the association between the distribution of income and the rate of overdose death is explained by the direct effect of income inequality on the rate of drug overdose death [direct effect $=0.21$ ], whereas $64 \%$ of the association is indirect and mediated by levels of environmental disorder, levels of police activity and the quality of the built environment [indirect effect $=(-0.55 \times-0.40)+(0.34 \times 0.09)+(0.36 \times 0.36)$ $=0.38]$. According to the model, as income inequality increases, environmental neighborhood disorder and police activity increase and the quality of the built environment declines; these variables are subsequently associated with the rate of drug overdose. The root mean square error of approximation of the model was 0.046 , suggesting a very good fit (Steiger, 1990).

\section{Discussion}

Neighborhood-level income inequality may be an important determinant of overdose death independent 
of individual-level factors. In this analysis we showed that the level of environmental disorder, the level of police activity and the quality of the built environment in a neighborhood partially mediate this association; after adjusting for these three intermediaries the odds of death due to drug overdose in neighborhoods in the top decile of income inequality decreased from 1.63 to 1.12 when compared to the most equitable neighborhoods. In path analyses we showed that income inequality produces a small direct effect on the rate of drug overdose mortality, but a large indirect effect through the level of environmental disorder and the quality of the built environment in a neighborhood:

\section{Neighborhood environmental disorder and police activity}

Public peace - the sidewalk and street peace — of cities is not kept primarily by the police, necessary as police are. It is kept primarily by an intricate, almost unconscious, network of voluntary controls and standards among the people themselves, and enforced by the people themselves... No amount of police can enforce civilization where the normal casual enforcement of it has broken down. (Jacobs, 1961)

In her depiction of the intricate "street ballet" performed by the residents of her Greenwich Village neighborhood, Jane Jacobs imparts the importance of informal social control mechanisms and, in particular, the order of city streets and sidewalks, over and above traditional mechanisms such as policing. The use of informal social control, defined as the capacity of a group to self-regulate based on desired principles to realize collective goals (Janowitz, 1975), is scarcer in less socially cohesive neighborhoods (Sampson, Raudenbush, \& Earls, 1997). Neighborhood social cohesiveness is shaped by the broader structural context and political economy (Sampson et al., 1997). For instance, neighborhoods characterized by higher income inequality may be more likely to experience a destabilization of social cohesion (Yen \& Syme, 1999). The paucity of social control in less cohesive neighborhoods may diminish the community capacity to control group-level processes (Sampson et al., 1997) resulting in manifestations of both environmental and social neighborhood disorder (Skogan, 1990), marked by visible cues such as litter on the streets and criminal activity, respectively (Ross \& Jang, 2000). Visible signs of neighborhood disorder, in turn, are associated with increased levels of fear and mistrust among residents (Ross \& Jang, 2000; Skogan, 1990) which undermine the collective efficacy of a neighborhood, a measure of the mutual trust and willingness of residents to intervene on behalf of the common good (Sampson et al., 1997). Therefore, the level of disorder in a neighborhood may be an important mediator between neighborhood level income inequality and rates of drug overdose mortality.

We found that the level of environmental disorder in a neighborhood may be an important link between income inequality and the rate of accidental drug overdose mortality. Signs of physical neighborhood disorder reflect reductions in neighborhood social control and collective efficacy. For example, the presence of unclean sidewalks may discourage neighborhood residents from spending more time outdoors, thereby preventing neighbors from developing supportive relationships and from enforcing social control over acceptable behaviors (Cohen, Farley, \& Mason, 2003; Diez Roux, 2003). The breakdown of social control and the introduction of social norms more tolerant of drug use may increase drug overdose mortality by increasing the prevalence of risk factors for drug overdose. For example, neighborhoods with a diminished enforcement of social norms may allow the formation of large drug use networks, a documented risk factor for overdose (Latkin et al., 2004). Furthermore, reductions in collective efficacy may inhibit residents from intervening or calling for help when witnessing an overdose. Together, these effects may influence the likelihood of drug overdose mortality by increasing the rate of drug overdose and the likelihood of death conditional on drug overdose.

We found that the level of police activity in a neighborhood only marginally mediated the association between the distribution of income and the rate of overdose death. It is possible that this finding is due in part to the potentially variable association between levels of police activity and rates of drug overdose mortality. For instance, neighborhoods with more police activity may benefit from increased enforcement and have lower rates of drug overdose mortality. Conversely, several explanations suggest that higher levels of neighborhood police activity may be adversely associated with rates of drug overdose mortality. First, fears of police involvement have been implicated as primary reasons for both the reluctance of witnesses to overdose to call for help (Darke et al., 1996) and the injection of certain drug users in more secluded areas (Dovey 
et al., 2001), factors which likely contribute to mortality from drug overdose by delaying medical responses. This general fear and mistrust represents a decrease in social capital (Kawachi et al., 1997) and may be higher in areas characterized by higher income inequality and police activity. Second, assuming a correlation between the number of arrests in a neighborhood and the number of actual crimes, the level of police activity in a neighborhood may be a marker for the level of social disorder in a neighborhood. It consistently has been shown that areas characterized by higher income inequality are more likely to exhibit visible signs of social disorder, such as crime (Kaplan et al., 1996), which may reflect a weakening of the social fabric of the community (Kawachi \& Berkman, 2000). This challenge to the social environment in a neighborhood may be negatively associated with the health of its residents (Kawachi \& Berkman, 2000), and in this instance, could have contributed to accidental drug overdose mortality by undermining neighborhood collective efficacy and social support, factors negatively associated with riskier drug use behaviors (Zapka, Stoddard, \& McCusker, 1993) and the likelihood of reporting a history of overdose (Burns, Martyres, Clode, \& Boldero, 2004). Therefore, in neighborhoods with higher income inequality and more social disorder, decreases in efficacy and social support may be associated with riskier drug use practices and higher rates of drug overdose. Further research is necessary to clarify the mechanisms through which police activity and levels of social disorder influence the likelihood of fatal drug overdose.

\section{Quality of the built environment}

The study of the built environment and health began several decades ago (Shaw \& McKay, 1942) and associations between the quality of the built environment and several health outcomes, including cardiovascular disease (Diez Roux, 2003) and mental health problems (Evans, 2003), have now been documented. With respect to mortality from drug overdose, a recent study of NYC neighborhoods found that characteristics of the internal and external built environment predicted the likelihood of fatal drug overdose (Hembree et al., 2005). In our study, we found that the quality of the built environment was an important intermediary between income inequality and the rate of drug overdose mortality in a neighborhood.
In neighborhoods with higher income inequality the materialization of physical neighborhood qualities conducive to drug use and drug overdose may directly influence rates of drug overdose mortality. For example, neighborhoods with a greater abundance of housing units in disrepair may promote drug use in less exposed areas, a practice which may increase the likelihood of dying from an overdose (Dovey et al., 2001). The quality of the built neighborhood environment may also influence drug overdose mortality indirectly through the experience of psychosocial stress. For instance, using a construct for neighborhood disorder which included qualities of the built environment (e.g., presence of vacant housing), a recent study found that injection drug users in more disordered Baltimore neighborhoods had higher levels of depression and that depression was associated with greater injection frequency (Latkin, Williams, Wang, \& Curry, 2005). Together, these findings suggest that rates of drug overdose mortality in neighborhoods with higher income inequality may be partially explained by the quality of the built environment.

\section{Limitations}

There are several limitations to this study. First, with respect to measures, it is important to note that although we controlled for available relevant individual and neighborhood-level variables we did not have individual measures of socioeconomic status available. The effect of individual income on the association between income inequality and health is equivocal. While some studies have suggested that measures of individual-level income confound the association between income inequality and health (Gravelle, Wildman, \& Sutton, 2002), others studies have failed to replicate these findings (Wolfson, Kaplan, Lynch, Ross, \& Backlund, 1999), or have suggested that adjusting for individual income may over-control for the effects of income inequality that work through the nonlinear association between individual income and poor health (Blakely, Lochner, \& Kawachi, 2002). Nonetheless, it is possible that confounding by individual-level variables not considered in these analyses could explain some of the association between income inequality and the likelihood of drug overdose. Furthermore, we note that inference about the pathways linking income inequality and the likelihood of fatal drug overdose is limited by our proxy measures, which may overstate or understate the 
effects of the neighborhood constructs they were designed to approximate. For example, although our measures of environmental disorder and police activity were theoretically predicated, structural measures may not accurately capture the levels of environmental disorder or police activity perceived by neighborhood residents. Similarly, because our measure of the percent of housing units in dilapidated condition was based on an assessment of occupied housing units only, it is likely that our results understate the mediating effect of this variable on the relation between income inequality and the likelihood of drug overdose.

Second, with respect to our study design, we made use of existing data collected at different points in time, preventing the establishment of temporal links to the observed relations and limiting inference about the causal effect of neighborhood characteristics on the likelihood of drug overdose mortality. Although neighborhoods likely do not change quickly (Geronimus, Bound, \& Waidmann, 1999) and we expect our data to be a reasonable approximation of a cross-sectional data set, it is difficult to know how well this information represents conditions of neighborhoods in NYC over time and whether any changes may account for some of the observed associations. Additionally, although the use of different surveys to collect data on our independent and dependent variables may have reduced the possibility of same-source bias, the cross-sectional nature of our study may have introduced the possibility of self-selection bias. It is possible that drug users may have migrated to areas with higher crime rates and neighborhoods in more distressed physical states, areas that in this analysis showed higher levels of income inequality. Studies employing a longitudinal design are necessary to establish temporal associations and rule out the possibility of self-selection bias. Furthermore, information about the time of residence in a particular neighborhood could be useful for drawing inference related to the lag time between exposure and outcome, as well as for assessing threshold or dose-response effects. Another potential limitation with respect to our study design relates to the aptness of CDs for representing neighborhoods. Although CDs are considered the administrative units that most closely approximate neighborhood boundaries, smaller neighborhood level units may have facilitated the measure of small-area characteristics and been more appropriate for assessing the factors mediating the observed relation between income inequality and drug overdose mortality. Further research should explore the use of alternative methods, such as the use of multilevel measures of variation, to evaluate the relevance of income inequality at administrative boundaries with various levels of spatial aggregation (Merlo, 2003).

Finally, with respect to the theoretical underpinnings of our study and the congruity of our model, inference related to the causality of our findings is limited by the intricate interplay of physical, material and social variables that complicate the distinction between mediating and confounding variables. Our hypotheses and the constructs and the pathways defined in these analyses were based on current hypotheses about the link between income inequality and health outcomes (Kawachi \& Kennedy, 1999). Nonetheless, it is possible that the effects of income inequality on the likelihood of drug overdose operate differently from how we posited.

\section{Conclusions}

Notwithstanding these limitations, our findings suggest that the level of environmental disorder and the quality of the built environment in a neighborhood may partially mediate the association between income inequality and the likelihood of drug overdose. By showing that physical and social neighborhood characteristics may represent important links in the association between the distribution of income and drug overdose mortality, these findings identify potential targets for interventions aimed at reducing the adverse impact of income inequality on the rate of drug overdose mortality. Interventions aimed at mitigating this impact must be designed to address the specific pathways between the distribution of income and the likelihood of drug overdose mortality. For example, given our finding that the quality of the built environment may be an important factor linking income inequality and the likelihood of fatal drug overdose, different solutions would be indicated depending on whether physically deteriorated neighborhoods influence the rate of drug overdose mortality directly by promoting drug use in unexposed areas or indirectly through the psychosocial stress process. In the former case, efforts such as sealing off abandoned building conceivably could reduce drug overdose mortality by preventing overdoses from occurring in areas less accessible to witnesses or emergency services; 
however, in the latter case successful interventions would have to necessarily improve the quality of the built environment in order to reduce drug overdose mortality associated with the distribution of income. While preliminary evidence suggests that housing improvements plausibly may help to reduce the adverse impact of income inequality on drug overdose mortality by increasing levels of social support and collective efficacy and reducing levels of psychosocial stress (Dalgard \& Tambs, 1997), further longitudinal work is necessary to elucidate the pathways between income inequality and social and environmental factors relevant to drug overdose mortality. Future research may also investigate the role of the pathways mentioned here in the relations between neighborhood level income inequality and the risk of other morbidity and mortality.

\section{Acknowledgments}

This work was partly funded by Grants DA 06534, DA 017642, and DA 018061 from the National Institute of Health.

\section{References}

Ahern, J., Pickett, K. E., Selvin, S., \& Abrams, B. (2003). Preterm birth among African American and white women: A multilevel analysis of socioeconomic characteristics and cigarette smoking. Journal of Epidemiology and Community Health, 57, 606-611.

Bennett, G. A., \& Higgins, D. S. (1999). Accidental overdose among injecting drug users in Dorset, UK. Addiction, 94, 1179-1190.

Blakely, T. A., Lochner, K., \& Kawachi, I. (2002). Metropolitan area income inequality and self-rated health - a multi-level study. Social Science \& Medicine, 54, 65-77.

Bureau of the Census. (1990). Census summary tape, file $3 A$ (STF $3 A$ ). Washington, DC:US Department of Commerce. http:// www.census.gov/ftp/pub/populatin/www/estimates/ co_crh.html.

Bureau of the Census. (1999). NYC housing and vacancy survey. Washington, DC:US Department of Commerce. http://landview.census.gov/hhes/www/nychvs.html.

Burns, J. M., Martyres, R. F., Clode, D., \& Boldero, J. M. (2004). Overdose in young people using heroin: Associations with mental health, prescription drug use and personal circumstances. The Medical Journal of Australia, 181, S25-S28.

Centers for Disease Control and Prevention. (2004). Unintentional and undetermined poisoning deaths - 11 states, 1990-2001. MMWR. Morbidity and Mortality Weekly Report, 53, 233-238.

Cohen, D. A., Farley, T. A., \& Mason, K. (2003). Why is poverty unhealthy? Social and physical mediators. Social Science \& Medicine, 57, 1631-1641.
Dalgard, O., \& Tambs, K. (1997). Urban environment and mental health: A longitudinal study. The British Journal of Psychiatry, 171, 530-536.

Darke, S., \& Hall, W. (2003). Heroin overdose: Research and evidence-based intervention. Journal of Urban Health, 80, 189-200.

Darke, S., Ross, J., \& Hall, W. (1996). Overdose among heroin users in Sydney, Australia: II. Responses to overdose. Addiction, 91, 413-417.

Diez Roux, A. (1998). Bringing context back into epidemiology: Variables and fallacies in multilevel analysis. American Journal of Public Health, 88, 216-222.

Diez Roux, A. (2003). Residential environments and cardiovascular risk. Journal of Urban Health, 80, 569-589.

Dovey, K., Fitzgerald, J., \& Choi, Y. (2001). Safety becomes danger: Dilemmas of drug-use in public space. Health \& Place, 7, 319-331.

Evans, G. W. (2003). The built environment and mental health. Journal of Urban Health, 80, 536-555.

Galea, S., Ahern, J., Vlahov, D., Coffin, P. O., Fuller, C., Leon, A. C., et al. (2003). Income distribution and risk of fatal drug overdose in New York City neighborhoods. Drug and Alcohol Dependence, 70, 139-148.

Galea, S., Freudenberg, N., \& Vlahov, D. (2005). Cities and population health. Social Science \& Medicine, 60, 1017-1033.

Geronimus, A. T., Bound, J., \& Waidmann, T. A. (1999). Health inequality and population variation in fertility-timing. Social Science \& Medicine, 49, 1623-1636.

Gravelle, H., Wildman, J., \& Sutton, M. (2002). Income, income inequality and health: What can we learn from aggregate data? Social Science \& Medicine, 54, 577-589.

Hembree, C., Galea, S., Ahern, J., Tracy, M., Markham Piper, T., Miller, J., et al. (2005). The urban built environment and overdose mortality in New York City neighborhoods. Health \& Place, 11, 147-156.

Infoshare Online. Community Studies of New York, Inc. http:// www.infoshare.org.

Jacobs, J. (1961). The death and life of great American cities. New York: Random House.

Janowitz, M. (1975). Sociological theory and social control. American Journal of Sociology, 81, 82-108.

Joe, G. W., \& Simpson, D. D. (1987). Mortality rates among opioid addicts in a longitudinal study. American Journal of Public Health, 77, 347-348.

Kaplan, G. A., Pamuk, E. R., Lynch, J. W., Cohen, R. D., \& Balfour, J. L. (1996). Inequality in income and mortality in the United States: Analysis of mortality and potential pathways. British Medical Journal, 312, 999-1003.

Kawachi, I., \& Berkman, L. F. (2000). Social cohesion, social capital, and health. In L. F. Berkman, \& I. Kawachi (Eds.), Social epidemiology. New York: Oxford University.

Kawachi, I., \& Kennedy, B. P. (1999). Income inequality and health: Pathways and mechanisms. Health Services Research, 34, 215-227.

Kawachi, I., Kennedy, B. P., Lochner, K., \& Prothrow-Stith, D. (1997). Social capital, income inequality and mortality. American Journal of Public Health, 87, 1491-1498.

Latkin, C. A., Hua, W., \& Tobin, K. (2004). Social network correlates of self-reported non-fatal overdose. Drug and Alcohol Dependence, 73, 61-67.

Latkin, C. A., Williams, C. T., Wang, J., \& Curry, A. D. (2005). Neighborhood social disorder as a determinant of drug 
injection behaviors: A structural equation modeling approach. Health Psychology, 24, 96-100.

Lynch, J., Smith, G. D., Harper, S., Hillmeier, M., Ross, N., Kaplan, G. A., et al. (2004). Is income inequality a determinant of population health? Part 1. A systematic review. The Milbank Quarterly, 82, 5-99.

Lynch, J. W., Smith, G., Kaplan, G. A., \& House, J. S. (2000). Income inequality and mortality: Importance to health and individual income, psychosocial environment, or material conditions. British Medical Journal, 320, 1200-1204.

Marmot, M. (2002). The influence of income on health: Views of an epidemiologist. Does money really matter? Or is it a marker for something else? Health Affairs, 21, 31-46.

Marzuk, P. K., Tardiff, K., Leon, A. C., Hirsch, C. S., Stajic, M., Portera, L., et al. (1997). Poverty and fatal accidental drug overdoses of cocaine and opiates in New York City: An ecological study. The American Journal of Drug and Alcohol Abuse, 23, 221-228.

Merlo, J. (2003). Multilevel analytical approaches in social epidemiology: Measures of health variation compared with traditional measures of association. Journal of Epidemiology and Community Health, 57, 550-552.

NYC Mayor's Office of Operations. (2002). Fiscal 2002 Mayor's Management Report. http://www.nyc.gov/mmr.

Ross, C. E., \& Jang, S. J. (2000). Neighborhood disorder, fear, and mistrust: The buffering role of social ties with neighbors. American Journal of Community Psychology, 28, 401-420.

Sampson, R. J., Raudenbush, S. W., \& Earls, F. (1997). Neighborhoods and violent crime: A multilevel study of collective efficacy. Science, 277, 918-924.

Sergeev, B., Karpets, A., Sarang, A., \& Tikhonov, M. (2003). Prevalence and circumstances of opiate overdose among injection drug users in the Russian Federation. Journal of Urban Health, 80, 212-219.

Shaw, C. R., \& McKay, H. D. (1942). Juvenile delinquency and urban areas: A study of the rates of delinquents in relation to differential characteristics of local communities in American cities. Chicago: University of Chicago Press.
Sinha, R. (2001). How does stress increase risk of drug abuse and relapse? Psychopharmacology, 158, 343-359.

Skogan, W. G. (1990). Disorder and decline. Berkeley: University of California Press.

Soobader, M.-J., \& LeClere, F. B. (1999). Aggregation and the measurement of income inequality: Effects of morbidity. Social Science \& Medicine, 48, 733-744.

Steiger, J. M. (1990). Structural equation model evaluation and modification: An interval estimation approach. Multivariate Behavioral Research, 25, 173-180.

Subramanian, S. V., \& Kawachi, I. (2004). Income inequality and health: What have we learned so far? Epidemiologic Reviews, 26, 78-91.

Warner-Smith, M., Darke, S., \& Day, C. (2002). Morbidity associated with non-fatal heroin overdose. Addiction, 97, 963-967.

Weich, S., Blanchard, M., Prince, M., Burton, E., Erens, B., \& Sproston, K. (2002). Mental health and the built environment: Cross-sectional survey of individual and contextual risk factors for depression. The British Journal of Psychiatry, 180, 428-433.

Wilkinson, R. G. (1997). Comment: Income, inequality, and social cohesion. American Journal of Public Health, 87, 1504-1506.

Wilkinson, R. G., \& Pickett, K. E. (2006). Income inequality and population health: A review and explanation of the evidence. Social Science \& Medicine, 62(7), 1768-1784.

Wolfson, M., Kaplan, G., Lynch, J., Ross, N., \& Backlund, E. (1999). Relation between income inequality and mortality: Empirical demonstration. British Medical Journal, 319, 953-957.

Yen, I. H., \& Syme, S. L. (1999). The social environment and health: A discussion of the epidemiologic literature. Annual Review of Public Health, 20, 287-308.

Zapka, J. G., Stoddard, A. M., \& McCusker, J. (1993). Social network, support and influence: Relationships with drug use and protective AIDS behavior. AIDS Education and Prevention, 5, 352-366.

Zeger, S. L., \& Liang, K.-Y. (1986). Longitudinal data analysis for discrete and continuous outcomes. Biometrics, 42, 121-130. 